\title{
The Impact of the Level of the Intestinal Short Chain Fatty Acids in Inflammatory Bowel Disease Patients Versus Healthy Subjects
}

\author{
N. Huda-Faujan ${ }^{1,3}$, A.S. Abdulamir ${ }^{2,3}$, A.B. Fatimah*, ${ }^{*}$, O. Muhammad Anas ${ }^{4}$, M. Shuhaimi ${ }^{5}$, \\ A.M. Yazid ${ }^{6}$ and Y.Y. Loong ${ }^{7}$
}

${ }^{I}$ Food Biotechnology Programme, Faculty of Science and Technology, Universiti Sains Islam Malaysia, Bandar Baru Nilai, 71800 Nilai, Negeri Sembilan, Malaysia; ${ }^{2}$ Institute of Bioscience, Department of Microbiology; ${ }^{3}$ Medical Microbiology Department, Faculty of Medicine, Alnahrain University, Iraq; ${ }^{4}$ Food Science Department, Faculty of Food Science and Technology, ${ }^{5}$ Halal Products Research Institute; ${ }^{6}$ Food Service and Management Department, Faculty of Food Science and Technology; ${ }^{7}$ Medicine Department, Faculty of Medicine and Health Sciences, Universiti Putra Malaysia, 43400 Serdang, Selangor, Malaysia

\begin{abstract}
The aim of this study was to determine the changes of short chain fatty acids (SCFAs) in faeces of inflammatory bowel disease (IBD) patients compared to healthy subjects. SCFAs such as pyruvic, lactic, formic, acetic, propionic, isobutyric and butyric acids were analyzed by using high performance liquid chromatography (HPLC). This study showed that the level of acetic, $162.0 \mu \mathrm{mol} / \mathrm{g}$ wet faeces, butyric, $86.9 \mu \mathrm{mol} / \mathrm{g}$ wet faeces, and propionic acids, 65.6 $\mu \mathrm{mol} / \mathrm{g}$ wet faeces, decreased remarkably in IBD faecal samples when compared with that of healthy individuals, 209.7, 176.0, and $93.3 \mu \mathrm{mol} / \mathrm{g}$ wet faeces respectively. On the contrary, lactic and pyruvic acids showed higher levels in faecal samples of IBD than in healthy subjects. In the context of butyric acid level, this study also found that the molar ratio of butyric acid was higher than propionic acid in both faecal samples. This might be due to the high intake of starch from rice among Malaysian population. It was concluded that the level of SCFAs differ remarkably between faecal samples in healthy subjects and that in IBD patients providing evidence that SCFAs more likely play an important role in the pathogenesis of IBD.
\end{abstract}

Keywords: Organic acid, human faecal, IBD, HPLC.

\section{INTRODUCTION}

Short chain fatty acids (SCFAs), are carboxylic acids with 1 to 6 carbon atoms that include different other functional groups, such as hydroxyl or dicarboxyl. In human, SCFAs arise from bacterial fermentation of carbohydrates, proteins, peptides and glycoprotein precursors [1,2]. SCFAs such as acetic, propionic and butyric acids are mainly formed during microbial fermentation of carbohydrate in the colon $[3,4]$. The most important role of SCFAs in colonic physiology is their trophic effect on the intestinal epithelium. For example, Sakata reported that the presence of SCFAs in rat colon stimulates mucosal proliferation [5]. In human, SCFAs production from inulin-type fructan can increase the metabolic activity, pointing to trophic effects for colonocytes [6].

Approximately $80-90 \%$ of SCFAs, which are produced from the breakdown of dietary food, are absorbed in colon while the rest are excreted in faeces [7]. SCFAs content in faeces could be used as a biomarker for the physiological processes in the organisms as well as for the effect of nutritional interventions [1]. The level of SCFA content in faecal samples have been shown to be related with some diseases such as IBD, irritable bowel syndrome (IBS),

*Address correspondence to this author at the Food Science Department, Faculty of Food Science and Technology, Universiti Putra Malaysia, 43400 Serdang, Selangor, Malaysia; Tel: 00-60-(0)3-89468375; Fax: 00-60-(0)389423552; E-mail: fatimah_upm_fst@yahoo.com cardiovascular disease (CVD), diarrhoea [8], and cancer [9]. For example, a decreased level of butyric acid in the colonocytes has been suggested to contribute to the genesis of ulcerative colitis (UC) [10]. It was also reported that increased lactic acid may modulate diarrhea in UC [11]. In addition, faecal SCFAs, acetic and propionic acids, in patients with diarrhea-dominant IBS were found to be of lower levels than in healthy individuals $[12,13]$.

Therefore, there has been increasing evidence that the majority of SCFAs play an essential role in maintaining the health of colonic mucosa. However, butyric, acetic, and propionic acids have mainly been emphasized. In particular, butyric acid was addressed to be more beneficial for promoting colonic health and more effective for stimulating the proliferation of intestinal mucosal cells than acetic and propionic acids [5]. Butyric acid is also the main energy substrate for the colonocytes [14] and it has been suggested to play an important role in the prevention and treatment of distal UC [10], Crohn's disease (CD) [15], and cancer [16]. In addition, butyric acid appears to induce differentiation of tumor cell lines [17].

Several methods were used to analyze the faecal SCFAs in rat and human samples. For example, a rapid and reliable gas chromatographic (GC) method has been developed and validated by Zhao et al. to determine eight SCFAs, in the colonic and faecal samples of rats and humans [18]. In addition, methods such as vacuum ultrafiltration followed by GC, ion chromatography (IC) [19], and IC with solid-phase 
extraction [20] were used for the determination of SCFAs in faecal samples. Furthermore, Scheppach et al. measured SCFAs by gas-liquid chromatography using a capillary column after purifying the faecal samples by acid vacuum transfer and concentration by alkaline freeze-drying [21]. In addition to $\mathrm{GC}$, high performance liquid chromatography (HPLC) has also been applied to the analysis of faecal SCFAs in humans [22, 23] and rats [24]. HPLC is convenient for the quantification of SCFAs, and it is less time-consuming [25]. Moreover, it does not require any prepurification steps when compared to GC [26].

In South East Asia, particularly in Malaysia, IBD has been not very common but the incidence of the disease was recently increasing. Based on the two types of IBD, UC was found to be more common than $\mathrm{CD}$ [27]. To date, data on IBD cases in South East Asia is still scarce in that very few studies, if any, were conducted on the content and the role of SCFAs in faeces of healthy and IBD subjects. Therefore, the current study was conducted to determine the level of faecal SCFAs (pyruvic, lactic, acetic, formic, propionic, butyric and isobutyric acids) in IBD patients by using HPLC methods. The level of each faecal SCFA was compared to counterpart samples from healthy individuals.

\section{MATERIALS AND METHODOLOGY}

\section{Chemicals and Reagents}

Formic acid, 98-100\%, and acetic acid, 100\%, were obtained from Merck (Merck, KGaA, Darmstadt, Germany), pyruvic acid, 99\%, and propionic acid, 99\%, were obtained from Merck (Merck, DHG, Hohenbrunn, Germany), isobutyric acid, 99\%, was obtained from Sigma (SigmaAldrich, St. Louis, CA, USA), lactic acid, 100\%, and butyric acid, 99.5\%, were purchased from Fluka (Cheniou, Gmblt, Germany).

\section{The Study Population and Faecal Samples}

Faecal samples were obtained from 50 healthy subjects $($ male $=18$, female $=32)$ and 8 IBD $($ male $=6$, female $=2)$ subjects from March 2007 to December 2008 in Selangor, Malaysia. The age of the studied patients ranged from 34 to 68 years and the age for the healthy subjects ranged from 22 to 55 years. Six of IBD patients were at remission phase except for $2 \mathrm{UC}$ were at active phase; nevertheless, all of the involved patients showed no diarrheal symptoms within 2 weeks before the time of sampling. The nutritional status of the involved patients was within average and patients did not change their nutritional habit during sampling. The IBD samples were collected from patients who had been diagnosed as CD $(n=2)$ and UC $(n=6)$. Diagnosis of IBD was confirmed in all cases by colonoscopy and histology. The main symptoms of the involved IBD patients within the last month were: for UC, loose stools (1 patients), low grade fewer ( 2 patients), mild diarrhea with blood stain (1 patient), abdominal pain (1 patients), and abdominal distension (1 patients), for $C D$, patients did not have remarkable symptoms. Furthermore, IBD patients did not experience any extra-intestinal manifestations. It is noteworthy to mention that IBD patients and the healthy volunteers did not receive antibiotics, probiotics, and prebiotics one month prior to the samples collection. Moreover, IBD patients did not receive mesalazine 2 weeks before sampling.
The faecal samples were collected into clean sterile containers. They were immediately taken to the laboratory and kept frozen at $-20^{\circ} \mathrm{C}$ for analysis. Dealing with human subjects was carried out within the scope of the ethical principles of biomedical research. The ethics committee of the University Putra Malaysia and Serdang Hospital and all of the involved subjects signed formal written consents.

\section{Preparation of Samples for Analysis}

The SCFAs of faecal samples were extracted as described by Lee et al. method [28] with slight modification. Faecal samples of weight $0.2 \mathrm{~g}$ were used and diluted at ratio 1:4 to $1: 8(\mathrm{w} / \mathrm{v})$ in sterile distilled water. The samples were then vortexed for $1 \mathrm{~min}$ and the homogenate was centrifuged at $10,000 \mathrm{~g}$ for $10 \mathrm{~min}$. The SCFA-containing supernatant was filtered through cellulose acetate membrane with a pore size of $0.2 \mu \mathrm{m}$ (GyroDisc CA; Orange Scientific) and stored at $-20^{\circ} \mathrm{C}$ until HPLC analysis.

\section{Determination of Organic Acids}

SCFAs analyses were carried out by using HPLC. Briefly, $40 \mu \mathrm{l}$ of faecal samples extraction were injected directly into HPLC System (Shimadzu LC-10AD Liquid Chromatography) with Shimadzu SPD-6A UV-VIS detector (Shimadzu, Kyoto, Japan). SCFA in faecal samples were separated using an ionic exchange resin, Aminex HPX-87H column, (Aminex HPX-87H, 300 x 7.8 mm, Bio-Rad Laboratories, Richmond, USA) at $65^{\circ} \mathrm{C}$. The target compounds were detected using a UV detector set at wavelength of $210 \mathrm{~nm}$. Filtered $0.01 \mathrm{~N} \mathrm{H}_{2} \mathrm{SO}_{4}$, through 0.45 $\mu \mathrm{m}$ nylon membrane, was used as a mobile phase at a flow rate of $0.6 \mathrm{ml} / \mathrm{min}$.

\section{Preparation of Calibration Standard Curve}

Quantification of SCFAs in faecal samples was carried out using external calibration standard curves method. Seven calibration standards were prepared at six levels of concentration ranging from $0.005 \mathrm{M}$ to $0.03 \mathrm{M}$ for pyruvic acid, $0.01 \mathrm{M}$ to $0.06 \mathrm{M}$ for formic acid and acetic acid, and $0.02 \mathrm{M}$ to $0.12 \mathrm{M}$ for lactic acid, propionic acid, isobutyric acid and butyric acid. The reference samples were injected repeatedly for nine times to measure the retention time. The calibration curves were constructed by plotting the relative peak area versus the molarity of solution. Faecal SCFA concentrations were expressed as mean $\mu$ mol per gram wet weight faeces using the following equation as described by Hoshi et al. [29] with modification.

Faecal SCFA $(\mu \mathrm{mol} / \mathrm{g})=$ [organic acid in faecal contents $(\mathrm{mmol} / \mathrm{ml}) \mathrm{X} \mathrm{V}_{\mathrm{d}}(\mathrm{ml}) \mathrm{X} 1000 \mathrm{l} / \mathrm{Wet}$ weight faeces $(\mathrm{g})$

Whereas: $\mathrm{V}_{\mathrm{d}}=$ Total Volume of Dilution

\section{Statistical Analysis}

Data analysis was conducted using MINITAB version 14 (Minitab Inc., PA, USA). The normality of data was checked using Anderson-Darling test before statistical analysis was done. Differences between means of SCFA concentration between healthy and IBD groups were analyzed by using unpaired Student's $t$-test. The means were considered statistically significant at $P<0.05$. Data was expressed in mean \pm SEM ( $\mu \mathrm{mol} / \mathrm{g}$ wet faeces $)$. 


\section{RESULT}

\section{Validation of Retention Time for Analytical Methods}

The reference standard in different concentrations was analyzed on three different days to show the retention times. Since external standard was used for calibration, the method requires precise analytical technique and requires that the detector sensitivity must be constant from day to day if the calibration curve is to remain valid [30]. Samples were injected nine times in different concentrations and the average of retention time $\left(\mathrm{R}_{\mathrm{t}}\right)$ was used. From the analysis, the $\mathrm{R}_{\mathrm{t}}$ for pyruvic, lactic, formic, acetic, propionic, isobutyric and butyric acids was 9.28, 12.07, 13.38, 14.60, 17.28, 19.49 , and $21.82 \mathrm{~min}$ respectively.

\section{Short Chain Fatty Acids in Faecal Samples}

The mean concentrations of SCFA in faecal samples of healthy and IBD subjects are shown in Table 1. From the table, results revealed that the mean concentrations of butyric and propionic acids, 86.9 and $65.6 \mu \mathrm{mol} / \mathrm{g}$ wet faeces, respectively in IBD faecal samples were lower than in healthy subjects, 176.0 and $93.3 \mu \mathrm{mol} / \mathrm{g}$ wet faeces respectively $(P<0.05)$. Acetic acid was also lower in faecal samples of IBD patients than of healthy subjects but the difference was not so significant $(p=0.16)$.

The faecal concentration of formic acid, isobutyric, lactic and pyruvic acids were also determined and compared between healthy and IBD groups. Formic acid was only detected in five healthy subjects and isobutyric acid was only detected in two samples of healthy group while no detection of formic and isobutyric acids was found in the faecal samples of IBD patients. In contrary, the faecal concentration of lactic and pyruvic acids was lower in healthy subjects, $24.5 \mu \mathrm{mol} / \mathrm{g}$ and $0.5 \mu \mathrm{mol} / \mathrm{g}$ respectively, than in IBD patients, $73.5 \mu \mathrm{mol} / \mathrm{g}$ and $2.1 \mu \mathrm{mol} / \mathrm{g}$ respectively, but this difference was not significant $(P$ $>0.05)$.

\section{Molar Ratio of Main SCFA in Faecal Samples}

There has been no report about the molar ratio of main SCFAs in faecal samples in Malaysian subjects. Therefore, the molar ratio of acetic, propionic and butyric acids were calculated. From the current study, the molar ratio of acetic: propionic: butyric acids in faecal samples of healthy subjects were 45:20:38 and in faecal samples of IBD were 49:20:27. This finding showed that the molar ratio of butyric acid and propionic was 1.5 and 1.35 in healthy and IBD subjects, respectively.

\section{DISCUSSION}

In this study, it was shown that butyric and propionic acids were decreased significantly in IBD subjects. This finding was similar to that reported by Takaishi et al. [22] who revealed that the concentrations of butyric and propionic acids were significantly decreased in IBD patients than in healthy controls. In addition, Vernia et al. [11] and Hallert et al. [31] reported similar decreasing trend of butyric acid in UC patients. However, another study reported that although there was a decreased butyric acid level in active UC, the difference was not significant between healthy and patients groups [32]. The decreasing level of butyric acid could be due to the assumption that the distribution of intestinal microbiota changes in IBD patients [22]. Furthermore, it was reported that the faecal proportion of butyric acid in patients with UC increased after consuming oat bran [3]. It was stated that the increase in butyric acid level may have an advantage to play a role in the prevention of UC [10]. Moreover, it was suggested that when the butyric acid is low in UC patients, the risk of colon cancer increases [33]. On the other hand, the increasing propionic acid was shown to be associated with decreasing serum cholesterol in blood [34].

Comparing acetic acid concentration between healthy and IBD faecal samples, Takaishi et al. also reported that the acetic acid in IBD faeces was not significantly lower than in healthy control and they found that the concentration of acetic acid in CD was lower than in UC [22]. This report was consistent with that reported by Stein et al. [35] that the amount of acetic acid in faecal samples of CD was lower (135.9 $\mu \mathrm{mol} / \mathrm{g}$ dry faeces, $n=8)$ than in healthy subjects (161.9 $\mu \mathrm{mol} / \mathrm{g}$ dry faeces, $n=10)$. Furthermore, Nilsson et al. reported that the mean level of acetic acid in healthy subjects $(n=20)$ before giving oat bran diet was $54.2 \mu \mathrm{mol} / \mathrm{g}$ wet faeces ranging from $19.5 \mu \mathrm{mol} / \mathrm{g}$ to $126.2 \mu \mathrm{mol} / \mathrm{g}$ of faeces [36]. They showed that, after 8 weeks of giving oat bran, the mean level of acetic acid increased $77.2 \mu \mathrm{mol} / \mathrm{g}$ wet faeces

Table 1. SCFA in Faecal Samples of IBD Patients and Healthy Subjects

\begin{tabular}{|c|c|c|c|c|c|c|c|}
\hline & Healthy Subjects $(n=50)$ & Range & $\% \mathbf{P C}^{*}$ & IBD Subjects $(\mathrm{n}=8)$ & Range & $\% \mathbf{P C}$ & $P$-values \\
\hline Acetic Acid & $209.7 \pm 14.0$ & $21.5-400.5$ & $(100)$ & $162.0 \pm 28.0$ & $64.2-308.9$ & $(100)$ & 0.160 \\
\hline Butyric Acid & $176.0 \pm 16.0^{*}$ & $45.2-503.3$ & $(100)$ & $86.9 \pm 21.0^{*}$ & $32.7-204.2$ & $(100)$ & 0.004 \\
\hline Propionic Acid & $93.3 \pm 5.3^{*}$ & $33.8-185.1$ & $(100)$ & $65.6 \pm 5.3^{*}$ & $45.1-91.7$ & $(100)$ & 0.001 \\
\hline Lactic Acid & $24.5 \pm 4.8$ & $0-120.6$ & $(48)$ & $73.5 \pm 37.0$ & $0-254.4$ & $(62.5)$ & 0.237 \\
\hline Formic Acid & $21.5 \pm 9.7$ & $0-364.2$ & $(10)$ & No detection & & & \\
\hline Pyruvic Acid & $0.5 \pm 0.3$ & $0-16.4$ & (8) & $2.1 \pm 1.3$ & $0-10.1$ & $(37.5)$ & 0.261 \\
\hline Isobutyric Acid & $17.9 \pm 13.2$ & $0-591.3$ & (4) & No detection & & & \\
\hline
\end{tabular}

$* \mathrm{PC}=$ Positive cases.

Results are expressed in $\mu \mathrm{mol} / \mathrm{g}$ wet faeces (mean \pm SEM).

Value marked with asterisk are significantly different between two groups $(P<0.05)$ 
ranging from 22.9 to $125.6 \mu \mathrm{mol} / \mathrm{g}$ of faeces $(P<0.001)$. And acetic acid absorption in the colon has been shown to increase cholesterol synthesis. However, addition of propionate to acetate resulted in no significant rise in cholesterol [37]. This finding was supported by Wong et al. [38] that the acetate: propionate ratio may reduce serum lipids and possibly decrease cardiovascular disease risk.

With respect to lactic acid, the current study yielded similar results to a previous report stating that higher lactic acid concentration was found in both of faecal UC and CD samples than in healthy subjects [8]. High concentration of lactic acid was associated with higher risk of diarrhoea and mucosal inflammation [2]. Previously, a study reported that faecal lactate rises in patients with acidorrhea [39]. The importance of low lactic acid concentration in faecal samples of healthy subjects is still unknown. However, lactic acid can be further metabolized by propionibacteria to propionic acid and acetic acid [40]. Butyric acid can be also produced from lactic acid through the acetyl-CoA pathway [41].

In this study, faecal formic acid was only detected in five healthy subjects. Quantification of formic acid in faecal samples was always unsatisfactory and frequently at very low or undetectable level [42]. This might be attributed to the fact that formic acid has been believed to be formed by microorganisms in the colon only at the initial phase of dietary fermentation [43]. Furthermore, formic acid is an intermediate product, not an end-product, of bacterial fermentation and is converted readily to $\mathrm{CO}_{2}$ and water [44]. Furthermore, formic acid was probably metabolised by bacterial enzymes during incubation at $50^{\circ} \mathrm{C}$. In addition, it is extremely volatile and losses cannot be avoided during preparation of sample. For these reasons formic acid in faeces is rarely detected [42].

Takaishi et al. [22] and Vernia et al. [8] showed that pyruvic and succinic acids in faecal IBD were higher than in healthy subjects and they found that the concentration of pyruvic acid in patients with UC was significantly higher than in patients with $\mathrm{CD}$. Their findings are similar to that of current study that pyruvic acid was higher in faecal IBD than in healthy group. However, this increase was not significantly different.

Other SCFAs such as iso-butyric, $n$-valeric, iso-valeric and $n$-caproic acids were presented in minor amounts in the human colon. Similarly, it was reported that all these SCFAs were too low to be detected [45]. The branched chain fatty acids (BCFA), iso-butyric and iso-valeric acids are primarily produced from catabolism of protein particularly from branched amino acids fermentation [46]. An increase of BCFA tends to be observed only when carbohydrate is limited [47].

Approximately, these SCFAs account for 90 to $95 \%$ of total fatty acids. Of the SCFAs, the major products are acetic, propionic, and butyric acids which are commonly found in proportions approximately 60:20:20 (acetic: propionic: butyric) $[1,38]$. However, these ratios are very rare to achieve in practice. The patterns of the molar ratio of SCFA awere ttributed to the bacterial species present. In addition, it was also influenced by the composition of diet and type of indigestible carbohydrates [3]. Moreover, the molar ratio of butyric and propionic acids was 1.5 and 1.35 in healthy and IBD subjects which might be due to the high intake of starch from rice among the Malaysian people.

The possible anti-inflammatory mechanism of SCFAs, namely propionic, butyric, and acetic acids, are still not clarified adequately. However, a recent study showed that propionic and butyric acids were equipotent, whereas acetic acid was less effective, at suppressing NF-kappaB reporter activity, inflammation-related gene expression and cytokine release in vitro. Therefore, these findings suggested that propionic and acetic acids, in addition to butyric acid, could be useful in the treatment of inflammatory disorders, including IBD [48]. Moreover, it was shown that butyric acid suppresses nuclear factor-kappaB activation via GPR109A receptors in normal and cancer colon cell lines as well as in normal mouse colon. This study showed that GPR109A mediates the tumor-suppressive effects of the bacterial fermentation product, butyric acid in colon [49]. In addition, it was confirmed that SCFA, adenine nucleotides, and phospholipids can modulate intestinal epithelial repair mechanisms. Given that repeated damage and injury of the intestinal surface are key features of various intestinal disorders including inflammatory bowel diseases, SCFA are essential for the constant repair of the colon epithelium [50].

\section{CONCLUSION}

From this study, it was concluded that the level of SCFAs might play an important role in the pathophysiology and/or progression of IBD. The current study showed that the level of SCFAs differs remarkably between the faecal samples of healthy subjects and these of IBD patients. As compared to the healthy subjects, acetic, butyric and propionic acids decreased dramatically in faecal samples of IBD as well as formic and isobutyric acids were not detectable in faecal samples of IBD while the level of acetic and pyruvic acids increased in faeces of IBD patients. In this study, the molar ratio of butyric acid also showed higher proportion than propionic acid in faecal samples and might be due to the high intake of starch from rice among Malaysian. However, future studies need larger sample size to determine more precisely the distribution of SCFAs among IBD patients in the region of South East Asia. The relationship between rice consumption and the reduction of IBD incidence also need to be determined since the incidence of IBD in the region of South East Asia is still not very common.

\section{REFERENCES}

[1] Garcia, A.; Olmo, B.; Lopez-Gonzalvez, A.; Cornejo, L.; Rupérez, F.J.; Barbas, C. Capillary electrophoresis for short chain organic acids in faeces. References values in a Mediterranean elderly population. J. Pharmaceut. Biomed. Anal., 2008, 46, 356-361.

[2] Cummings, J.H.; Macfarlane, G.T.; Englyst, H.N. Prebiotic digestion and fermentation. Am. J. Clinic. Nutr., 2001, 73, 415S420S.

[3] Henningsson, A.M.; Björck, I.M.; Nyman, E.M. Combinations of indigestible carbohydrates affect short-chain fatty acid formation in the hindgut of rats. J. Nutr., 2002, 132, 3098-3104.

[4] Cummings, J.H. The Large Intestine in Nutrition and Disease., $2^{\text {nd }}$ ed. Institut Danone: Bruxelles, 2001.

[5] Sakata, T. Stimulatory effect of short-chain fatty acids on epithelial cell profeliration in the rat intestine: a possible explanation for trophic effects of fermentable fibre, gut microbes and luminal trophic factors. Br. J. Nutr., 1987, 58, 95-103.

[6] Sauer, J.; Richter, K.K.; Pool-Zobel, B.L. Products formed during fermentation of the prebiotic inulin with humangut flora enhance 
expression of biotranformation genes in human primary colon cells. Br. J. Nutr., 2007, 97, 928-937.

[7] Ruppin, H.; Bar-Meir, S.; Soergel, K.H.; Wood, C.M.; Schmitt, M.G. Jr. Absorption of short-chain fatty acids by the colon. Gastroenterology, 1980, 78, 1500-1507.

[8] Venter, C.S.; Vorster, H.H.; Cummings, J.H. Effects of dietary propionate on carbohydrate and lipid metabolism in healthy volunteers. Am. J. Gastroenterol., 1990, 85, 549-553.

[9] Floch, M.H.; Hong-Curtiss, J. Probiotics and functional foods in gastrointestinal disorders. Curr. Treat. Options Gastroenterol., 2002, 5, 311-321.

[10] Cummings, J.H. Short-chain fatty acid enemas in the treatment of distal ulcerative colitis. Eur. J. Gastroenterol. Hepatol., 1997, 9, 149-153.

[11] Vernia, P.; Gnaedinger, A.; Hauck, W.; Breuer, R.I. Organic anions and the diarrhea of inflammatory bowel disease. Dig. Dis. Sci., 1988, 33, 1353-1358.

[12] Treem, W.R.; Ahsan, N.; Kastoff, G.; Hyams, J. Fecal short-chain fatty acids in patients with diarrhea-predominant irritable Bowel syndrome: in vitro studies of carbohydrate fermentation. J. Pediatr. Gastroenterol. Nutr., 1996, 23, 342-374.

[13] Mortensen, P.B.; Andersen, J.R.; Arffmann, S.; Krag, E. Shortchain fatty acids and the irritable bowel syndrome: the effect of wheat bran. Scand. J. Gastroenterol. 1987, 22, 185-192.

[14] Roediger, W.E.W. Utilization of nutrients by isolated epithelial cells of the rat colon. Gastroenterology, 1982, 83, 424-429.

[15] Di Sabatino, A.; Morera, R.; Ciccocioppo, R.; Cazzola, P.; Gotti, S.; Tinozzi, F.P.; Tinozzi, S; Corazza, G.R. Oral butyrate for mildly to moderately active Crohn's disease. Aliment. Pharmacol. Ther., 2005, 22, 789-794.

[16] Scheppach, W.; Bartram, H.P.; Richter, F. Role of short chain fatty acids I prevention of colorectal cancer. Eur. J. Cancer, 1995, 31, 1077-1080.

[17] Barnard, J.A.; Warwick, G. Butyrate rapidly induces growth inhibition and differentiation in HT-29 cells. Cell Growth Differ., 1993, 4, 495-501.

[18] Zhao, G., Nyman, M. and ÅkeJönsson, J. Rapid determination of short-chain fatty acids in colonic contents and faeces of humans and rats by acidified water-extraction and direct-injection gas chromatography. Biomed. Chromatogr., 2005, 20, 674-682.

[19] Chen, H.M; Lifschitz, C.H. Preparation of fecal samples for assay of volatile fatty acids by gas-liquid chromatography and highperformance liquid chromatography. Clin. Chem., 1989, 35, 74-76.

[20] Horspool, L.J.; McKellar, Q.A. Determination of short-chain fatty acids in equine caecal liquor by ion exchange high performance liquid chromatography after solid phase extraction. Biomed. Chromatogr., 1991, 5, 202-206.

[21] Scheppach, W.M.; Fabian, C.E.; Kasper, H.W. Fecal short-chain fatty acid (SCFA) analysis by capillary gas-liquid chromatograph. Am. J. Clin. Nutr. 1987, 46, 641-646.

[22] Takaishi, H.; Matsuki, T.; Nakazawa, A.; Takada, T.; Kado, S.; Asahara, T.; Kamada, N.; Sakuraba, A.; Yajima, T.; Higuchi, H.; Inoue, N.; Ogata, H.; Iwao, Y.; Nomoto, K.; Tanaka, R.; Hibi, T. Imbalance in intestinal microflora constitution could be involved in the pathogenesis of inflammatory bowel disease. Int. J. Med. Microbiol., 2008, 298, 463-472.

[23] Al-Tamimi, M.A.H.M.; Palframan, R.J.; Cooper, J.M.; Gibson, G.R; Rastall, R.A. In vitro fermentation of sugar beet arabinan and arabinooligosaccharides by the human gut microflora. J. Appl. Microbiol., 2006, 100, 407-414.

[24] Morita, T.; Kasaoka, S., Oh-hashi; A., Ikai, M.; Numasaki, Y.; Kiriyama, S. Resistant proteins alter cecal short-chain fatty acid profiles in rats fed high amylase cornstarch. J. Nutr., 1998, 128, 1156-1164.

[25] Ewaschuk, J.B.; Zello, G.A.; Naylor, J.M; Brocks, D.R. Metabolic acidosis: separation methods and biological relevance of organic acids and lactic acid enantiomers. J. Chromatogr. B., 2002, 781, 39-56.

[26] Jham, G.N.; Fernandes, S.A.; Garcia, C.F.; Silva, A.A. Comparison of GC and HPLC for the quantification of organic acids in coffee. Phytochem. Anal., 2002, 13, 99-104.

[27] Ouyang, Q.; Tandon, R.; Goh, K.L.; Ooi, C.J.; Ogata, H.; Fiocchi, C. The emergence of inflammatory bowel disease in the Asian Pacific region. Curr. Opin. Gastroenterol., 2005, 21, 408-413.
[28] Lee, J.H.; Lee, S.K.; Park, K.H.; Hwang, I.K.; Ji, G.E. Fermentation of rice using amylolytic Bifidobacterium. Int. J. Food Microbiol., 1999, 50, 155-161.

[29] Hoshi, S.; Sakata, T.; Mikuni, K.; Hashimoto, H.; Kimura, S. Galactosyl-sucrose and xylosylfructoside alter digestive tract size and concentrations of cecal organic acids in rats fed diets containing cholesterol and cholic acid. J. Nutr., 1994, 124, 52-60.

[30] Rounds, M. A.; Nielsen, S. S. In Food Analysis. Nielsen, S.S. Ed. $2^{\text {nd }}$ ed. Kluwer Academic/ Plenum Publishers: New York, 1999, p. 505 .

[31] Hallert, C.; Björck, I.; Nyman, M.; Pousette, A.; Granno, C.; Svensson, H. Increasing fecal butyrate in ulcerative colitis patients by diet: controlled pilot study. Inflam. Bowel Dis., 2003, 9, 116121.

[32] Den Hond, E.; Hiele, M.; Evenepoel, P.; Peeters, M.; Ghoos, Y.; Rutgeerts, P. In vivo butyrate metabolism and colonic permeability in extensive ulcerative colitis. Gastroenterology, 1998, 115, 584590.

[33] Farrell, R.J; Peppercorn, M.A. Ulcerative colitis. Lancet, 2002 359, 331-339.

[34] Venter, C.S., Vorster, H.H.; Cummings, J.H. Effects of dietary propionate on carbohydrate and lipid metabolism in healthy volunteers. Am. J. Gastroenterol., 1990, 85, 549-553.

[35] Stein, J.; Kulemeier, J.; Lembcke, B.; Caspary, W.F. Simple and rapid method for determination of short-chain fatty acids in biological materials by high-performance liquid chromatography with ultraviolet detection. J. Chromatogr., 1992, 576, 53-61.

[36] Nilsson, U.; Johansson, M.; Nilsson, A.; Björck, I.; Nyman, M. Dietary supplementation with B-glucan enriched oat bran increases faecal concentration of carboxylic acids in healthy subjects. Eur. J. Clin. Nutr., 2008, 62, 978-984.

[37] Wolever, T.M., Spadafora, P.; Eshuis, H. Interaction between colonic acetate and propionate in humans. Am. J. Clin. Nutr., 1991, 53, 681-687.

[38] Wong, J.M., de Souza, R., Kendall, C.W., Emam, A. Jenkins, D.J. Colonic health: fermentation and short chain fatty acids. Gastroenterology, 2006, 40, 235-243.

[39] Haemmerli, U.P.; Kistler, H.; Ammann, R.; Marthaler, T.; Semenza, G.; Auricchio, S.; Prader, A. Acquired milk intolerance in the adult caused by lactose malabsorption due to a selective deficiency of intestinal lactase activity. Am. J. Med., 1965, 38, 2730 .

[40] Macfarlane, G.T.; Cummings, J.H. In The Large Intestine: Physiology, Pathophysiology, and Disease, Philips, S.F. Ed. Raven Press, Ltd: London, 1997; pp. 51-52.

[41] Bourriaud, C.; Robins, R.J.; Martin, L.; Kozlowski, F.; Tenailleau, E.; Cherbut, C.; Michel, C. Lactate is mainly fermented to butyrate by human intetinal microfloras but inter-individual variation is evident. J. Appl. Microbiol., 2005, 99, 201-212.

[42] Mills, G.A., Walker, V.; Mughai, H. Headspace solid-phase microextraction with 1-pyrenyldiazomethane in-fibre derivation for analysis of faecal short-chain fatty acids. J. Chromatogr. B: Biomed. Sci. Appl., 1999, 730, 113-122.

[43] Pryde, S.E.; Duncan, S.H.; Hold, G.L.; Stewart, C.S.; Flint, H.J. The microbiology of butyrate formation in the human colon. FEMS Microbiol. Lett., 2002, 217, 133-139.

[44] Lifschitz, C.H.; Wolin, M.J.; Reeds, P.J. Characterization of carbohydrate fermentation in feces of formula-fed and breast-fed infants. Pediatr. Res., 1990, 27, 165-169.

[45] Wang, X.; Brown, I.L.; Khaled, D.; Mahoney, M.C.; Evans, A.J.; Conway, P.L. Manipulation of colonic bacteria and volatile fatty acid production by dietary high amilose maize (amylomaize) starch granules. J. Appl. Microbiol., 2002, 93, 390-397.

[46] Cardona, M.E.; Collinder, E.; Stern, S.; Tjellstrom, B.; Norin, E.; Midtvedt, T. Correlation between faecal iso-butyric and iso-valeric acids in different species. Microb. Ecol. Health Dis., 2005, 17, 177182.

[47] Ayesh, R.; Weststrate, J.A.; Drewitt, P.N; Hepburn, P.A. Safety evaluation of phytosterol esters. Part 5. Faecal short chain fatty acid and microflora content, faecal bacteria 1 enzyme activity and serum female sex hormones in healthy normolipidaemic volunteers consuming a controlled diet either with or without a phytosterol ester-enriched margarine. Food Chem. Toxicol., 1999, 37, 11271138.

[48] Tedelind, Specifications; Westberg, F.; Kjerrulf, M.; Vidal A. Antiinflammatory properties of the short-chain fatty acids acetate and 
propionate: a study with relevance to inflammatory bowel disease. World J. Gastroenterol., 2007, 13, 2826-2832.

[49] Thangaraju, M.; Cresci, G.A.; Liu, K.; Ananth, S.; Gnanaprakasam, J.P.; Browning, D.D.; Mellinger, J.D. Smith, S.B.; Digby, G.J.; Lambert, N.A.; Prasad, P.D.; Ganapathy, V. GPR109A is a Gprotein-coupled receptor for the bacterial fermentation product butyrate and functions as a tumor suppressor in colon. Cancer Res., 2009, 69, 2826-2832.

[50] Sturm, A.; Dignass, A.U. Epithelial restitution and wound healing in inflammatory bowel disease. World J. Gastroenterol., 2008, 14, 348-353

Received: November 30, 2009

(C) Huda-Faujan et al.; Licensee Bentham Open.

This is an open access article licensed under the terms of the Creative Commons Attribution Non-Commercial License (http://creativecommons.org/licenses/by-nc/3.0/) which permits unrestricted, non-commercial use, distribution and reproduction in any medium, provided the work is properly cited. 